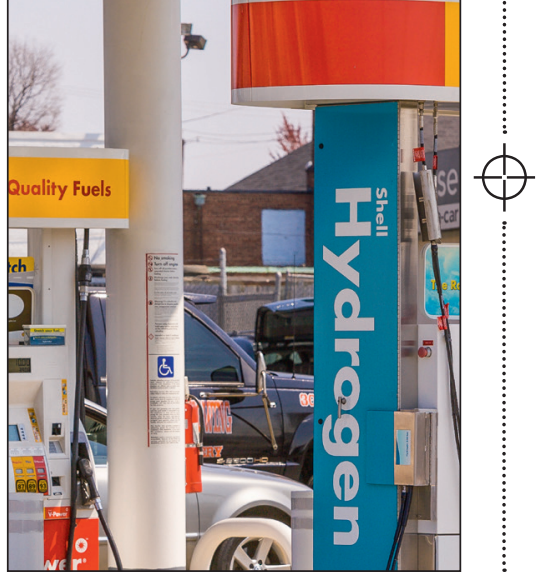

\title{
Materials challenges in the hydrogen cycle
}

\author{
By Tim Palucka \\ Feature Editor: Brian J. Ingram
}

$T^{\mathrm{h}}$ he term "hydrogen economy" was coined in 1970 by the University of Pennsylvania electrochemist Bernhardt Patrick John O'Mara Bockris. His vision was to provide clean power without the pollution generated by fossil fuel sources. Researchers have been exploring the hydrogen cycle since then, focusing on the need to efficiently generate, store, and distribute hydrogen for power generation, ammonia production, reduction of metals, and other applications. Materials development and discovery have been at the heart of these efforts. Perhaps the most successful technology has been the development and commercialization of fuel cells.

At a fundamental level, fuel cells react with hydrogen and oxygen to generate electricity while producing water. They are being deployed more widely in transportation, industry, and home use than you might realize. The reduction of fossil fuels and their resulting pollutants is driving clean transportation initiatives worldwide and playing a big role in ushering in the long-awaited hydrogen economy. But there are many challenges to be met to make fuel cells energy- and cost-efficient: reducing the amount of expensive platinum catalyst, finding suitable nanoporous solid adsorbents or metal hydrides to make hydrogen storage practical, and discovering the best way to assemble the five-layer fuel-cell sandwich (membrane in the middle, electrodes on either side of the membrane, and gas diffusion media outside the electrodes) at large scale.

Fuel cells are categorized by the membrane type and range from aqueous alkaline solutions, molten salts, polymers, to even solid crystalline materials. Two types of fuels cells - proton-exchange membrane (PEM) and solid-oxide fuel cells (SOFCs) - are widely used today and garner a lot of research investment. PEMs operate at a relatively low temperature $\left(80^{\circ} \mathrm{C}\right)$ and use a polymer membrane; SOFCs have a ceramic membrane and operate at a higher temperature $\left(800^{\circ} \mathrm{C}\right)$. Both have catalysts to accelerate hydrogen/ oxygen reaction. PEMs are used in transportation applications because the lower temperature makes startup instantaneous. With their higher temperature and longer startup time to reach it, SOFCs are more suitable for stationary, industrial applications. This article focuses on PEM fuel cells.

According to E4Tech's Fuel Cell Industry Review 2017, 72,600 fuel-cell units were shipped in 2017, broken down geographically by 56,800 units in Asia, 9900 in North America, 5100 in Europe, and 800 in the rest of the world. By application, 55,700 units were stationary, 12,000 were for transportation, and 4900 were portable units. The most common fuel cell shipped was the PEM variety

at 45,500 units, followed by 24,000 SOFCs, with the remainder consisting of minor quantities of other fuel-cell types. (E4Tech's report was based on firm shipment data from January to October 2017, with forecasts added for the rest of the year.)

\section{Hydrogen generation challenges from a manufacturer's point of view}

For fuel-cell-powered vehicles, generating hydrogen is the first step. Proton OnSite in Wallingford, Conn., produces commercial, low-temperature PEM water electrolysis systems for laboratories and industrial applications. Electrolysis of water involves decomposing water into oxygen and hydrogen using electric current. Generating hydrogen on-site eliminates the need to ship compressed hydrogen cylinders or liquid-hydrogen tube trailers to vehicle refueling sites. Kathy Ayers, vice president of R\&D at Proton OnSite, said that their hydrogengenerating equipment would work better with the development of polymer membranes and catalysts specifically designed for electrolysis. "Electrolysis technology has not really caught up with fuel-cell technology," said Ayers.

While generation of hydrogen by splitting water is essentially the reverse reaction of generating electricity using a fuel cell, they are not the same in practice, Ayers pointed out. Specifically, electrolysis involves a lot more water in the cell, while a fuel cell is relatively dry. The polymer electrode membrane soaks up water and swells. "When it swells excessively, it becomes mechanically weaker just because the polymer strands are farther apart, and it becomes more gel-like," said Ayers. "When we're operating at 30 bar [430 psi] or higher, the mechanical strength is not there unless you use pretty thick membranes ranging from 175 to 250 microns."

In contrast to this Nafion membrane thickness for electrolyzers, fuel-cell membranes of the same material are much thinner at 8-12 microns. But Nafion is a 40-year-old technology that was not designed for electrolysis. The field would benefit from thinner (50-60 micron) membrane materials with increased mechanical strength that could increase electrolysis cell efficiency; Researchers are beginning to respond to this need for electrolysis-specific polymers. They are investigating different polymer compositions and the number of functional groups to optimize ionic conductivity and decrease water uptake. For the polymer backbone, which affects the mechanical strength of the polymer, they are looking at replacing the fluorine-based backbone of Nafion with hydrocarbons.

Brian J. Ingram, Argonne National Laboratory, USA

Tim Palucka, tpalucka@gmail.com 
The catalysts used in electrolysis - platinum on the hydrogen side and iridium on the oxygen side - could use an upgrade to reduce cost and improve efficiency. "There hasn't been a lot of work to try to devise better catalysts specific for acidic electrolysis environments such as PEM/Nafion, so we're still using what GE used in the '60s and '70s," said Ayers. She noted that there has been a lot of recent work on catalysts for alkaline electrolysis systems, but this is of limited use to industry using ion-exchange membranes, since there are no stable basic membranes yet.

\section{Hydrogen-storage challenges for vehicular applications}

Once hydrogen is generated, it must be safely stored prior to use in a fuel cell. In this area, automotive manufacturers currently use carbon fiber-reinforced composite tanks filled with hydrogen gas pressurized to 700 bar (>10,00 psi), which has a system gravimetric capacity of $4.2 \mathrm{wt} \% \mathrm{H}_{2}$, a system volumetric capacity of $24 \mathrm{~g} \mathrm{H}_{2} /$ liter, and a cost of USD $\$ 15 / \mathrm{kWh}$. The "system" includes the tank and any plumbing in addition to the $\mathrm{H}_{2}$. It is physically impossible using 700 bar pressurized gas storage to meet the volumetric capacity target agreed upon by automobile manufacturers and the US Department of Energy. The ultimate targets are $6.5 \mathrm{wt} \% \mathrm{H}_{2}, 50 \mathrm{~g} \mathrm{H}_{2} /$ liter, and USD $\$ 8 / \mathrm{kWh}$. In the interest of safety, costs, and space, reducing the pressure from 700 bar to even 350 bar $(>5,000$ psi) would be a substantial improvement.

Reaching these energy density requirements and pressure limits calls for storing hydrogen in solid-state, nanoporous sorbent materials or metal hydrides in the fuel tank. The Hydrogen Materials Advanced Research Consortium (HyMARC), comprising six US national labs, has been charged with investigating the fundamental properties of these materials, including theoretical, numerical modeling, and experimental approaches.

"From the materials point of view, hydrogen storage is in what I like to call a 'no-man's land' of energy," said Mark Allendorf, senior scientist at Sandia National Laboratories and co-director of HyMARC. "Sorbents such as metal-organic frameworks and other nanoporous materials tend to bind hydrogen too weakly, whereas metal hydrides tend to bind the hydrogen too strongly and have either thermodynamic or kinetics limitations." This means that to achieve sufficient capacity, sorbents must store hydrogen at inconvenient liquid nitrogen temperatures. Alternatively, metal hydrides typically must be heated to too high a temperature to release the hydrogen.

On the hydrides side, researchers worldwide are exploring (1) binary hydrides, $\mathrm{MH}_{\mathrm{x}}(\mathrm{M}=$ main-group or transition metal, such as in $\left.\mathrm{LiH}, \mathrm{MgH}_{2}\right)$; (2) intermetallic hydrides, $\mathrm{AB} \mathrm{H}_{\mathrm{y}}(\mathrm{A}=$ hydriding metal and $\mathrm{B}=$ nonhydriding metal, such as $\mathrm{TiFeH}_{\mathrm{x}}$ and $\mathrm{LaNi}_{5} \mathrm{H}_{\mathrm{x}}$ ); and (3) complex metal hydrides, $\mathrm{MEH}_{\mathrm{x}}$, where $\mathrm{E}=$ boron (e.g., $\mathrm{LiBH}_{4}, \mathrm{Mg}\left(\mathrm{BH}_{4}\right)_{2}$ ), nitrogen (e.g., $\mathrm{LiNH}_{2}, \mathrm{Mg}\left(\mathrm{NH}_{2}\right)_{2}$ ), or aluminum (e.g., $\left.\mathrm{NaAlH}_{4}, \mathrm{Mg}\left(\mathrm{AlH}_{4}\right)_{2}\right)$. Considerable effort has gone into investigating nanostructured metal hydrides, whose advantages compared to bulk include improved reversibility, altered heats of hydrogen absorption/desorption, nanointerfacial reaction pathways with faster rates, and new surface states capable of activating chemical bonds.

"We're trying to come at this from both ends and figure out what the limiting factors are," said Allendorf. "For sorbents, we want to get the absorption energy and the volumetric capacity higher. Whereas for the hydrides, we're trying to destabilize them, make the thermodynamics more favorable, and remove some of the kinetic barriers that slow down the process even more." This research aims at tailoring the hydrides to meet the DOE targets, but for now, compressed hydrogen in carbon fiberreinforced composite fuel tanks is the only working option.

\section{The growing success of hydrogen-PEM fuel cells in transportation}

All this research into the hydrogen cycle is leading to greater adoption of fuel cells in the transportation sector. More than 5000 fuel-cell cars have been sold or leased in the state of California to date, where the 39th hydrogen fueling station was just opened in January 2019. For comparison, more than 512,000 battery-powered electric vehicles have been sold in California as of March 2019, with more than 15,000 battery-charging stations in the state as of January 2019.

One driving force for introducing PEMs in the transportation sector is that fuel-cell developers are determined to produce solutions that match or exceed the current products.

"In no way do we want to have to apologize or give compromised solutions for any fuel-cell challenges," said Keith Wipke, fuel-cell and hydrogen technologies laboratory program manager at the National Renewable Energy Laboratory (NREL). For instance, fueling a carbon fiber hydrogen tank up to 700 bar 
( $>10,000 \mathrm{psi}$ ) in 3 to 5 minutes is not trivial, but engineers worldwide set this goal to compete with gasoline fuel tank fill-ups for automobiles. The challenge was that moving so much hydrogen into the tanks raises the temperature by $40-50^{\circ} \mathrm{C}$, and carbon fiber tanks cannot exceed $85^{\circ} \mathrm{C}$. So the engineers started by cooling the hydrogen to $-40^{\circ} \mathrm{C}$ to keep the tank temperature within limits during the predictable heat-up. "The engineering solution was essentially designed around giving the consumer exactly what they're used to, which is a relatively quick fill-up at full speed,' said Wipke. Hydrogen from this fuel tank is fed into the fuel cell to drive the vehicle's powertrain.

He also noted that worldwide standards for nozzles and fueling protocols were agreed upon up front. "If you take a car that's made in the US to Japan and fill it at their station, it will fill safely and completely the same way it does here," said Wipke. As a further indication of the "no excuses" paradigm, hydrogen fuel-cell cars have a driving range similar to a gasoline vehicle, 480-640 km (300-400 miles) on one tank.

Despite this success, many technological and materials challenges remain to improve the generation, distribution, and storage of hydrogen and the manufacturability, durability, efficiency, and lifetime of fuel cells - all while reducing the cost. National laboratories, universities, and industry are conducting research to overcome these challenges.

\section{Manufacturability of fuel cells at scale}

As evidenced by the success of Japan's ENE-FARM fuel-cell commercialization program, which had deployed more than 120,000 residential fuel-cell units to heat and cool Japanese homes through 2014, high-quality fuel cells can be produced at demonstration or market-introduction scales. The PEM units can be exceptionally durable, achieving more than 60,000 hours (approximately seven years) of usable lifetime under daily cycling conditions.

However, companies pursuing markets that demand much higher annual volumes (e.g., automotive) are looking for further improvements in manufacturing technologies for PEMs. Remarkably, even at this stage in commercialization, there is a debate regarding the details of cell fabrication. The five-layer sandwich structure, with a membrane in the middle, electrodes on either side of the membrane, and gas diffusion media outside the electrodes, is standard. "But how you get there is a different question," said Michael Ulsh, fuel-cell manufacturing R\&D project lead at NREL. "How you build up those five layers, in terms of a sequence of manufacturing processes, is not at all uniformly agreed on right now."

In general, roll-to-roll processes are being used to manufacture the components of the five-layer structure. But variations exist, especially regarding fabrication of the electrode, which can include making either catalyst-coated membranes or gas diffusion electrodes.

The difference is whether you put the electrode onto the membrane or onto the gas diffusion media. "Those two different structures have different pluses and minuses that can depend on the intended operating conditions of the fuel cell," said Ulsh, "and it's really not understood yet which one might be optimal for performance or durability or, for that matter, processing and cost."

While most companies are looking at atmospheric pressure coating processes, at least one is exploring roll-to-roll manufacturing pathways under vacuum. Vacuum processes typically provide more control over atomic or molecular chemistry and structure than an atmospheric process and give manufacturers more ability to make coatings in a conformal way. "But the question is, can you do that at scale and cost?" asked Ulsh. With each innovation, the question of scalability returns.

Because platinum can account for up to a third of the cost of the catalyst, finding alternatives to platinum group metals would go a long way toward reducing the cost. Developing alternative polymers to Nafion for PEM cell membranes could increase ionic conductivity and improve the material strength of the membrane, especially for electrolysis applications. Many researchers are focusing on solid-state sorbents, metal hydrides, and other materials that can store hydrogen for distribution and in the fuel-cell tanks of automobiles.

On the manufacturing side, much work remains to define the optimal process for roll-to-roll manufacturing of five-layered fuel cells, including deciding whether putting the electrode onto the membrane or onto the gas diffusion media is a better practice. These challenges and more remain to make the hydrogen cycle of generation, distribution, and storage less costly and more efficient.

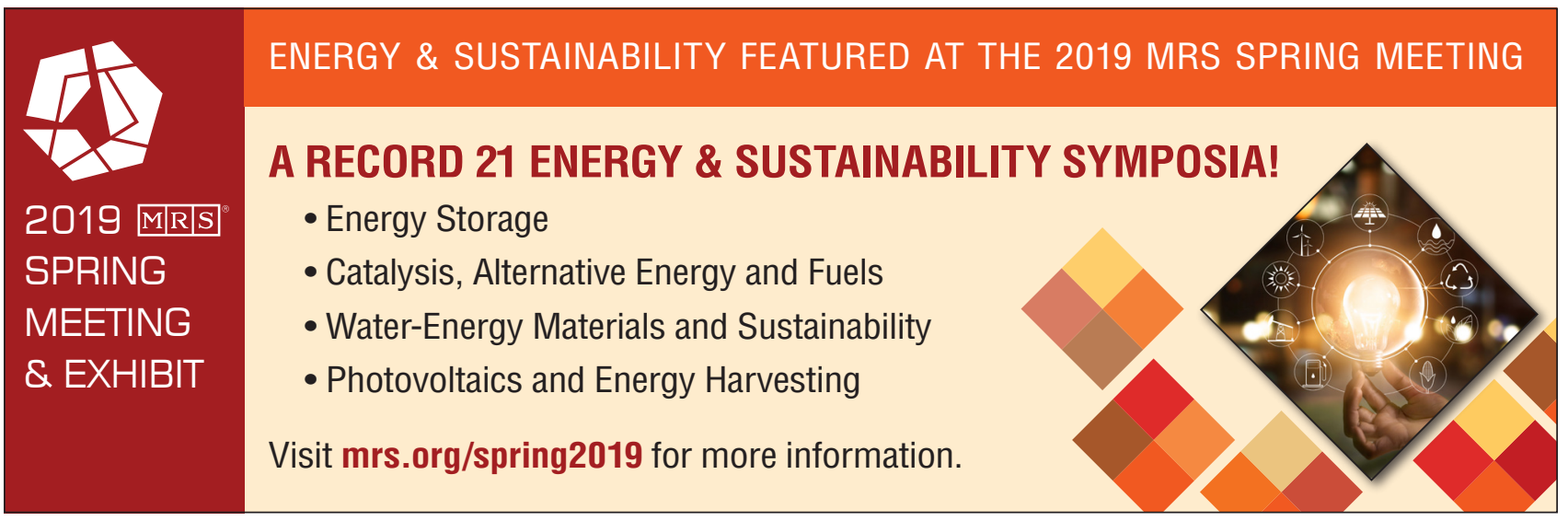

